ANL-6903

Mathematics and

Computers

(TID-4500, 35th Ed.)

AEC Research and

Development Report

ARGONNE NATIONAL LABORATORY

9700 South Cass Avenue

Argonne, Illinois 60440

A FORTRAN PROGRAM TO ANALYZE

MASS SPECTROMETER ION OPTICS

by

Kurt Kaiser

Chemistry Division

August 1964

Operated by The University of Chicago under

Contract W-31-109-eng-38

with the

U. S. Atomic Energy Commission 


\section{DISCLAIMER}

This report was prepared as an account of work sponsored by an agency of the United States Government. Neither the United States Government nor any agency Thereof, nor any of their employees, makes any warranty, express or implied, or assumes any legal liability or responsibility for the accuracy, completeness, or usefulness of any information, apparatus, product, or process disclosed, or represents that its use would not infringe privately owned rights. Reference herein to any specific commercial product, process, or service by trade name, trademark, manufacturer, or otherwise does not necessarily constitute or imply its endorsement, recommendation, or favoring by the United States Government or any agency thereof. The views and opinions of authors expressed herein do not necessarily state or reflect those of the United States Government or any agency thereof. 


\section{DISCLAIMER}

Portions of this document may be illegible in electronic image products. Images are produced from the best available original document. 
TABLE OF CONTENTS

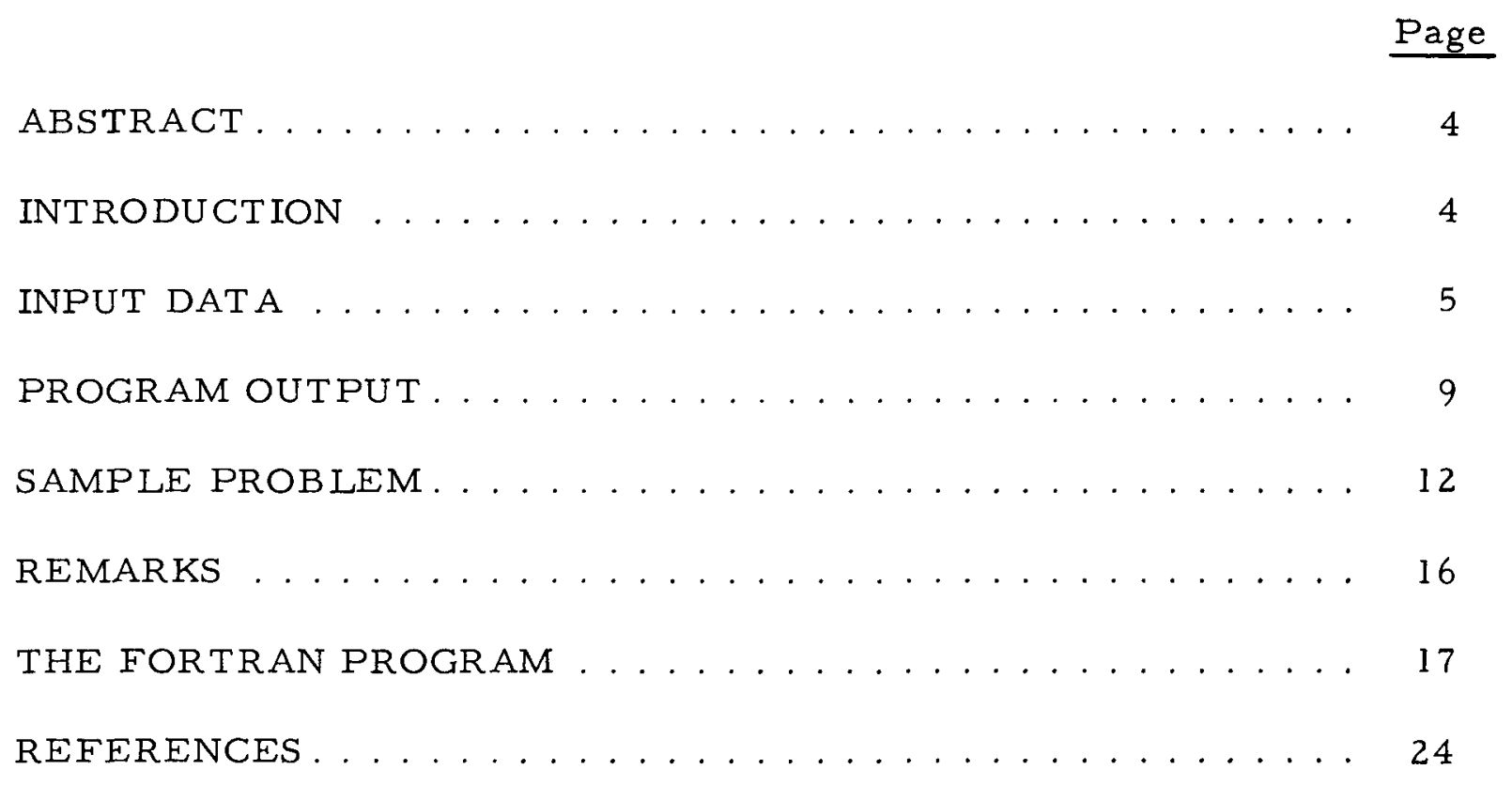




\section{LIST OF FIGURES}

No.

Title

Page

1. Figure Showing the Trajectories of Two Ions through an Electromagnetic Sector Field............... 5

2. Radial Section of a Magnetic Sector. . . . . . . . . . . 6

3. Toroidal Electrostatic Sector Field . . . . . . . . . . . 6

4. A Tandem Sector Field System ............... 8

5. Figure Illustrating the Direction and Energy Focusing Curves and the Angles these Curves Make with the Optic Axis . . . . . . . . . . . . . . . . . . 11

6. 100 in. Radius Double Focusing Mass Spectrometer....... 12

7. First-order Approximation to the Ion Trajectories for the Argonne 100-in. Mass Spectrometer........... 15

8. Fortran Program Flow Chart. ............... 18

\section{LIST OF TABLES}

No. Title Page

I. Input Data Card Format . . . . . . . . . . . 8

II. Input Data for Sample Problem. . . . . . . . . . . . . 13

III. Sample Problem Output. . . . . . . . . . . . . . . . . 14

IV. Fortran Program Listing .................. 19 


\title{
A FORTRAN PROGRAM TO ANALYZE \\ MASS SPECTROMETER ION OPTICS \\ by
}

Kurt Kaiser

\begin{abstract}
A Fortran programis described for the computation of ion-optical aberration coefficients through second order for any number of tandem electric and magnetic sector fields, such as those used in multistaged mass spectrometers. Also computed are the image positions and their magnifications, the system mass dispersion, and the inclinations of the direction- and energy-focusing planes with respect to the optic axis.
\end{abstract}

\section{INTRODUCTION}

Since 1950 extensive studies have been made of the ion-optical properties of tandem electric and magnetic sector fields by Johnson and Nier, (1) Voorhies, (2) Hintenberger and König, (3) Ewald and Liebl, (4) Tasman, Boerboom, and Wachsmuth, (5) and others. These studies formed the basis for the computer program described herein, although other results were derived when needed.

This program considers ions having the following initial conditions different from those of ions which traverse the systems optic axis (see Fig. 1):

(1) an initial angle to the optic axis

$\alpha$ in the radial direction;

$\alpha_{z}$ in the axial direction;

(2) a different velocity or energy

$\mathrm{V}=\mathrm{V}_{0}(1+\beta)$ or

$\mathrm{E}=\mathrm{E}_{0}(1+\eta)$;

(3) a different mass

$M=M_{0}(1+\gamma)$

(4) an initial displacement to the optic axis

$\delta$ in the radial direction;

$\delta_{z}$ in the axial direction. 


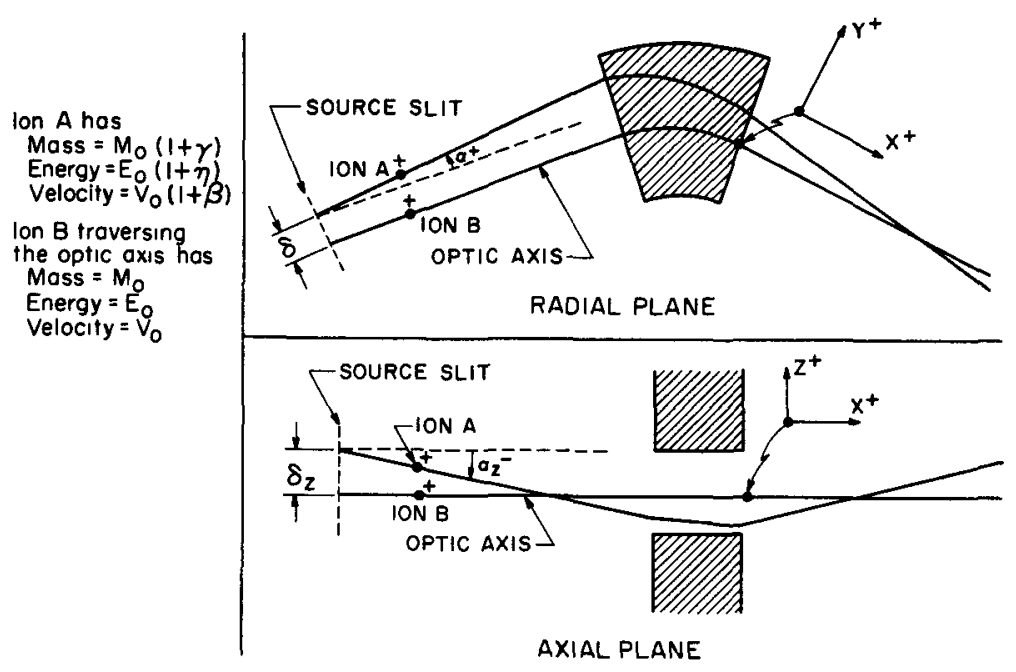

Fig. 1. Figure Showing the Trajectories of Two Ions through an Electromagnetic Sector Field. The initial displacement of ion A to the optic axis is resolved into the radial component $\delta$ and an axial component $\delta_{z}$. Also, its initial direction to the optic axis is resolved into radial and axial components $\alpha$ and $\alpha_{z}$, respectively.

The program calculates ion trajectories as functions of $\alpha, \beta, \gamma, \delta$, $\alpha_{z}$, and $\delta_{z}$. In the radial plane the trajectories are given as power series to second-order terms, and in the axial direction to first-order terms. In field-free regions the trajectories are straight lines given directly by the program output. Points along the trajectories in the sector fields can be found by subdividing the field into a number of tandem sector fields, zero distance apart, and reading out computed data for each edge of the subfields.

The electric sectors may have curved boundaries and toroidal shape, which includes cylindrical and spherical analyzers as special cases. The magnetic fields are assumed homogeneous, but can have non-normal entrance and exit, as well as circularly curved boundaries.

\section{INPUT DATA}

The input data to this program are punched on cards, one card for each field in the system. For convenience these data are divided into three types, each of which is discussed below.

TYPE I DATA: A set of parameters for each field specifying its configuration:

(1) For a homogeneous magnetic field, as shown in Fig. 2, the relevant parameters are the field radius $r_{m}$, the beam-deflection angle $\phi_{m}$, the 
radii of curvature of the entrance and exit boundaries, $R^{\prime}$, and $R^{\prime \prime}$, and the entrance and exit angles $\epsilon^{\prime}$, and $\epsilon^{\prime \prime}$. A radius of curvature is positive (negative) if the sector boundary is convex (concave) towards the field-free region. Consider a perpendicular drawn to the sector boundary where it intersects the system optic axis. Then the angle $\epsilon$ is positive (negative) if the optic axis is on the same (opposite) side of this perpendicular as the sector center of curvature.

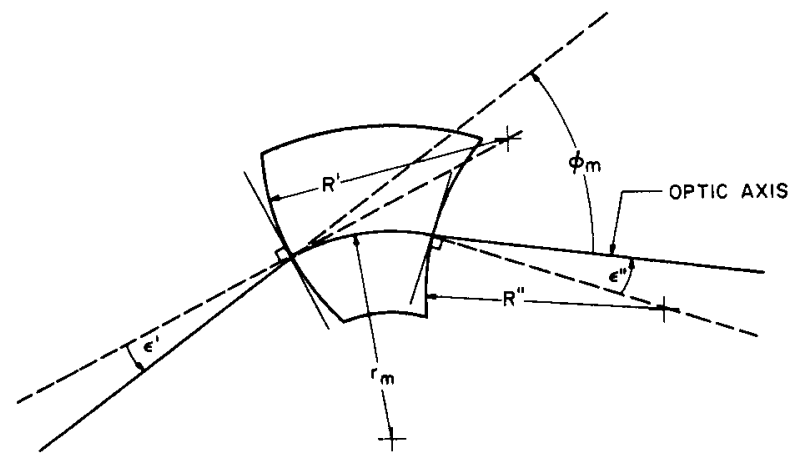

Fig. 2. Radial Section of a Magnetic Sector Field.

In this figure $R^{\prime}$ is positive, $R^{\prime \prime}$ is negative, $\epsilon^{\prime}$ is positive, and $\epsilon^{\prime \prime}$ is negative.

(2) For a toroidal electric field, as shown in Fig. 3, the parameters are the radius $r_{e}$, described by the optic axis, the beam-deflection angle $\phi_{e}$, the radii of curvature of the entrance and exit boundaries, $R_{I}$ and $R_{I I}$, and two parameters, $c$ and $R_{e}^{\prime}$, describing approximately the electric field in the neighborhood of the optic axis. Again, the radius of curvature of a boundary is positive (negative) if the sector boundary is convex (concave) towards the field-free region.

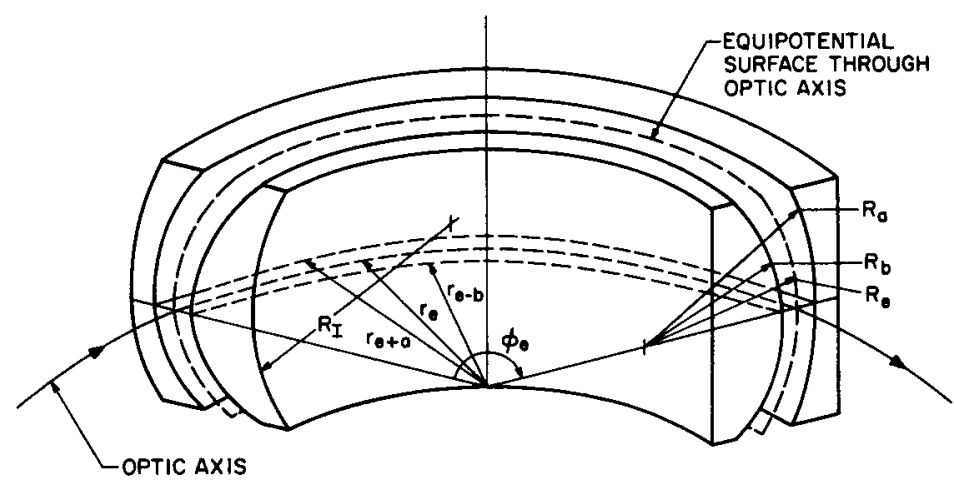

Fig. 3. Toroidal Electrostatic Sector Field. The entrance boundary has a positive curvature with its center of curvature in the Median plane.

The two parameters $\mathrm{c}$ and $\mathrm{R}_{e}^{\prime}$ are defined as follows: $c=r_{e} / R_{e}$, 
and

$$
R_{e}^{\prime}=\left(\frac{\partial R}{\partial r}\right)_{r=r_{e}, z=0},
$$

where $R$ is the radius of curvature of an equipotential surface near the optic axis and the other symbols are as defined in Fig. 3. The values of $c$ and $R_{e}^{\prime}$ for a general toroidal sector are discussed by Tasman $(6)$ and Albrecht. (7) To first order,

$$
c=\frac{r_{e}(a+b)}{b R_{a}+a R_{b}}
$$

and

$$
R_{e}^{\prime}=\frac{R_{a}-R_{b}}{a+b}
$$

Two special types of toroidal electric fields are frequently used: the cylindrical analyzer which has $c=0$ and $R_{e}^{\prime}=1$, and the spherical analyzer which has $c=1$ and $R_{e}^{1}=1$.

TYPE II DATA: A set of parameters describing the relation of each field to its neighbors (see Fig. 4):

(1) On the card for the first field, one enters the distance from the source slit to the first field entrance boundary $\left(\hat{l}^{\prime}\right)$.

(2) On the rest of the cards for the system, one enters the distance from the exit boundary of the previous field to the entrance boundary of the field considered (d), and also whether the deflection is in the same or opposite sense as that of the previous field.

(3) On the card for the last field in the system, one enters the dis tance ( $l$ ") from the exit boundary to the point where the program is to calculate the aberration coefficients. Henceforth, this point will be referred to as the collector point and the plane perpendicular to the optic axis at this point as the collector plane.

(4) On each field card enter the sequence number of each field along with the total number of fields in the system. 


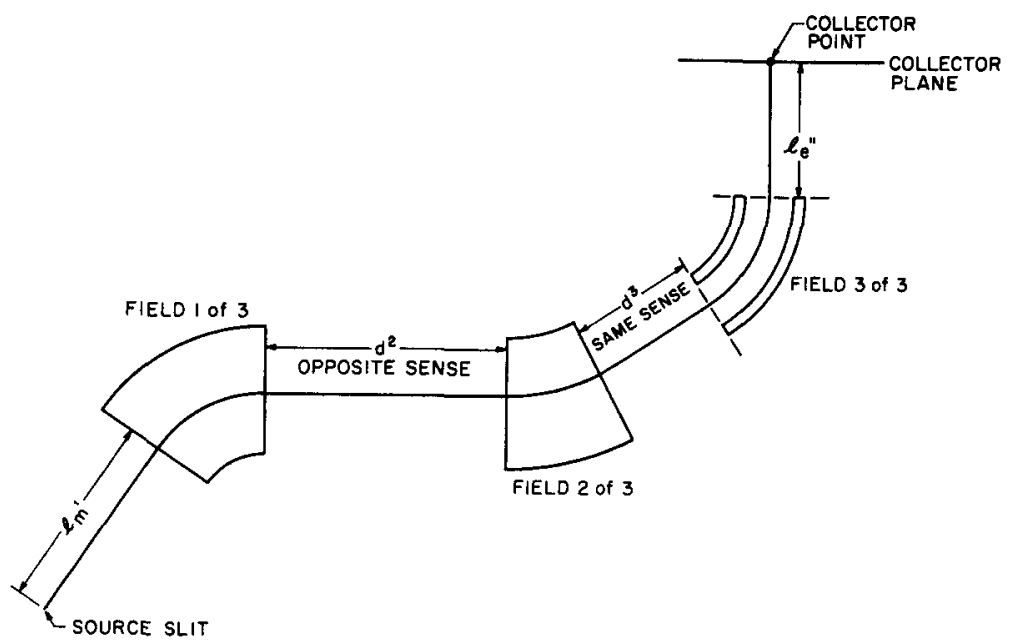

Fig. 4. A Tandem Sector Field System

TYPE III DATA: Digits for controlling the following program options:

(1) For a single symmetric field, the program can calculate both the entrance and the exit distances ( $l^{\prime}$ and $\left.l^{\prime \prime}\right)$, so the point of first-order angle $(\alpha)$ focus is the collector point.

(2) For any system of fields, the program can calculate the dis tance ( $($ "l) from the last field to the point of first-order angle $(\alpha)$ focus and use it as the collector point.

(3) The aberration coefficients can be calculated in terms of energy differences $\eta$ rather than velocity differences $\beta$.

(4) The coefficient and ray trace arrays, described under output, may be read out if desired.

A detailed listing of the data card format is given in Table I.

Table I

INPUT DATA CARD FORMAT

\begin{tabular}{|c|c|c|c|c|}
\hline $\begin{array}{l}\text { Card } \\
\text { Columns }\end{array}$ & Format & $\begin{array}{l}\text { Fortran } \\
\text { Symbol }\end{array}$ & Explanation & Punched on \\
\hline $1-6$ & $F 6.0$ & Q & Field deflection angle in degrees $\left(\phi_{\mathrm{e}}\right.$ or $\left.\phi_{\mathrm{m}}\right)$ & all cards. \\
\hline $7-12$ & $F 6.0$ & $\mathbf{R}$ & Field radius $\left(r_{\mathrm{e}}\right.$ or $\left.r_{\mathrm{m}}\right)$ & all cards. \\
\hline $13-18$ & $F 6.0$ & $\mathrm{DA}$ & $\begin{array}{l}\text { The distance from the source slit to the first field } \\
\left(\ell_{\mathrm{e}}^{\prime} \text { or } \ell_{\mathrm{m}}^{\prime}\right)\end{array}$ & $\begin{array}{l}\text { card for the first field only. } \\
\text { Not necessary at all if } 1 \text { is } \\
\text { punched in CC77. }\end{array}$ \\
\hline $19-24$ & F6.0 & DB & $\begin{array}{l}\text { The distance from the previous field to the } \\
\text { present field (d) }\end{array}$ & $\begin{array}{l}\text { all cards except the one for } \\
\text { the first field. }\end{array}$ \\
\hline $25-30$ & $F 6.0$ & $D C$ & $\begin{array}{l}\text { The distance from the last field to the point } \\
\text { where an aberration coefficient summary is } \\
\text { desired (collector point) (le or } \ell_{m}^{\prime \prime} \text { ) }\end{array}$ & $\begin{array}{l}\text { card for the last field only. } \\
\text { Not necessary at all if } 1 \text { is } \\
\text { punched in CC76. }\end{array}$ \\
\hline $31-36$ & $\mathrm{~F} 6.0$ & $\mathrm{Rl}$ & $\begin{array}{l}\text { The radius of curvature of the entrance field } \\
\text { boundary }\left(R^{\prime} \text { or } R_{T}\right)\end{array}$ & $\begin{array}{l}\text { all cards that do not have a } \\
2 \text { or } 3 \text { punched in CC74. }\end{array}$ \\
\hline $37-42$ & $F 6.0$ & R2 & $\begin{array}{l}\text { The radius of curvature of the exit field } \\
\text { boundary }\left(R^{n} \text { or } R_{\Pi}\right)\end{array}$ & $\begin{array}{l}\text { all cards that do not have a } \\
2 \text { or } 4 \text { punched in CC74. }\end{array}$ \\
\hline
\end{tabular}


Table I (Contd)

\begin{tabular}{|c|c|c|c|c|}
\hline $\begin{array}{l}\text { Card } \\
\text { Columns }\end{array}$ & Format & $\begin{array}{l}\text { Fortran } \\
\text { Symbol }\end{array}$ & Explanation & Punched on \\
\hline 43-48 & F60 & El & $\begin{array}{l}E^{\prime} \text { in degrees for a magnetıc fieid } \\
0 \text { for a cylındrical electrostatıc field } \\
1 \text { for a spherical electrostatic field } \\
c \text { parameter for a toroidal electrostatic field }\end{array}$ & $\begin{array}{l}\text { all cards except those mag- } \\
\text { netic field cards that have } \\
\varepsilon^{\prime}=0\end{array}$ \\
\hline $49-54$ & F60 & E2 & $\begin{array}{l}\varepsilon \text { " In degrees for a magnetic field } \\
1 \text { for a cylındrical or spherical electrostatıc } \\
\text { field } \\
R_{e}^{\prime} \text { parameter for a toroidal electrostatıc field }\end{array}$ & $\begin{array}{l}\text { all cards except those mag- } \\
\text { netic field cards that have } \\
\varepsilon^{\prime \prime}=0\end{array}$ \\
\hline $55-59$ & $5 x$ & & Not used & \\
\hline 60 & Il & I9 & $\begin{array}{l}\text { I In this column if the printer is to bring up a } \\
\text { new page before doing any more printing }\end{array}$ & $\begin{array}{l}\text { those cards where this } \\
\text { option is desired }\end{array}$ \\
\hline $61-66$ & I6 & $\mathrm{KI}$ & $\begin{array}{l}\text { The field number (fields to be numbered sequen- } \\
\text { tially beginning at the source end) }\end{array}$ & all cards \\
\hline $67-72$ & I6 & $\mathrm{K} 2$ & $\begin{array}{l}\text { The total number of fields in the particular } \\
\text { system considered }\end{array}$ & all cards \\
\hline 73 & Il & Il & 1 for a magnetic field, blank for an electric field & all cards \\
\hline 74 & Il & I2 & $\begin{array}{l}\text { I If } R 1 \text { and } R 2 \text { (CC 31-42) are both not equal to } \\
\text { infinity } \\
2 \text { if } R 1 \text { and } R 2 \text { (CC 31-42) are both equal to } \\
\text { infinity } \\
3 \text { if } R 1 \text { (CC } 31-36) \text { is equal to infinity and R2 } \\
\text { (CC 37-42) is not equal to infinity } \\
4 \text { if } R 1 \text { (CC 31-36) is not equal to infinity and } \\
R 2 \text { (CC 37-42) is equal to infinity }\end{array}$ & all cards \\
\hline 75 & Il & I3 & $\begin{array}{l}\text { I If the deflection is in the opposite sense as the } \\
\text { previous field, blank if it is in the same sense }\end{array}$ & $\begin{array}{l}\text { all cards except the one for } \\
\text { the first field. }\end{array}$ \\
\hline 76 & Il & I4 & $\begin{array}{l}\text { I If the program is to calculate the distance } \\
\text { from the last field to the Image plane which } \\
\text { gives first-order angle focusing - this distance } \\
\text { will be printed out llabeled DCl and used in } \\
\text { subsequent calculations }\end{array}$ & $\begin{array}{l}\text { card for the last field when } \\
\text { this option is desired }\end{array}$ \\
\hline 77 & Il & I5 & $\begin{array}{l}1 \text { If the program is to calculate the distance } \\
\text { from the source to the first field - this feature } \\
\text { can be used for a single symmetric field only }\end{array}$ & $\begin{array}{l}\text { field card on which this } \\
\text { option is wanted }\end{array}$ \\
\hline 78 & Il & I6 & $\begin{array}{l}\text { I If the aberrations are to be obtained in the } \eta \\
\text { (energy) representation, blank for aberrations } \\
\text { in the } \beta \text { (velocityl representation }\end{array}$ & $\begin{array}{l}\text { all cards blanks or ones } \\
\text { must be used consistently } \\
\text { throughout a system }\end{array}$ \\
\hline 79 & Il & I7 & 1 for the coefficient print feature & $\begin{array}{l}\text { card for field for which this } \\
\text { option is desired }\end{array}$ \\
\hline 80 & Il & I8 & 1 for the ray trace print feature & $\begin{array}{l}\text { card for field for which this } \\
\text { option is desired. }\end{array}$ \\
\hline
\end{tabular}

Notes

1 CC abbreviation for card column(s)

2 The distances required above may be measured in any consistent unit

\section{PROGRAM OUTPUT}

For each field-free space this program calculates the radial displacement $y$ to second order and the axial displacement $z$ to first order as a function of $\alpha, \beta, \gamma, \delta, \alpha_{z}$, and $\delta_{z}$ This is accomplished by calculating certain constants for each field, then altering the aberration coefficients by use of these constants with a subprogram.

After each field is calculated the coefficients may be read out through a program option This feature is called the coefficient print. 
If this option is elected, thirty-six coefficients are read out for each field, in the order $C_{1}$ to $C_{18}$, then $D_{1}$ to $D_{18}$. This output is labeled by $C$ followed by the field number. Specifically, the $C^{\prime} s$ and $D^{\prime} s$ are defined by the following equations, where the superscript

1 refers to the first field of a system,

$\ell$ refers to the last field of a system, and

$\mathrm{N}$ refers to the Nth field of a system:

$$
\begin{aligned}
Y^{N}= & r^{N}\left[C_{1}^{N} \alpha+C_{2}^{N} \beta+C_{3}^{N} \gamma+C_{4}^{N}\left(\frac{\delta}{r^{1}}\right)+C_{7}^{N} \alpha^{2}+C_{8}^{N} \alpha \beta+C_{9}^{N} \beta^{2}+C_{10}^{N} \alpha \gamma+C_{11}^{N} \beta \gamma+C_{12}^{N} \gamma^{2}\right. \\
& \left.+C_{13}^{N} \alpha\left(\frac{\delta}{r^{1}}\right)+C_{14}^{N} \beta\left(\frac{\delta}{r^{1}}\right)+C_{15}^{N}\left(\frac{\delta}{r^{1}}\right)^{2}+C_{16}^{N} \alpha_{z}^{2}+C_{17}^{N} \alpha_{z}\left(\frac{\delta_{z}}{r^{1}}\right)+C_{18}^{N}\left(\frac{\delta_{z}}{r^{1}}\right)^{2}\right] \\
& +x^{N}\left[D_{1}^{N} \alpha+D_{2}^{N} \beta+D_{3}^{N} \gamma+D_{4}^{N}\left(\frac{\delta}{r^{1}}\right)+D_{7}^{N} \alpha^{2}+D_{8}^{N} \alpha \beta+D_{9}^{N} \beta^{2}+D_{10}^{N} \alpha \gamma+D_{11}^{N} \beta \gamma\right. \\
& \left.+D_{12}^{N} \gamma^{2}+D_{13}^{N} \alpha\left(\frac{\delta}{r^{1}}\right)^{2}+D_{14}^{N} \beta\left(\frac{\delta}{r^{1}}\right)+D_{15}^{N}\left(\frac{\delta}{r^{1}}\right)^{2}+D_{16}^{N} \alpha_{z}^{2}+D_{17}^{N} \alpha_{z}\left(\frac{\delta_{z}}{r^{1}}\right)+D_{18}^{N}\left(\frac{\delta_{z}}{r^{1}}\right)^{2}\right] \\
z^{N}= & r^{N}\left[C_{5}^{N} \alpha_{z}+C_{6}^{N}\left(\frac{\delta_{z}}{r^{1}}\right)\right]+X^{N}\left[D_{5}^{N} \alpha_{z}+D_{\frac{1}{N}}^{N}\left(\frac{\delta_{z}}{r^{1}}\right)\right]
\end{aligned}
$$

In these equations $r$ is a field radius, $\mathrm{X}^{\mathrm{N}}$ is the distance along the optic axis measured from the exit boundary of the Nth field, and $\mathrm{Y}^{\mathrm{N}}$ and $\mathrm{Z}^{\mathrm{N}}$ are the displacements measured in a plane located at $X^{N}$ perpendicular to the optic axis. Note that $\mathrm{Y}^{\mathrm{N}}$ is positive on the opposite side of the optic axis from the field center of curvature, $\mathrm{Z}^{\mathrm{N}}$ is positive if above the optic axis, and $\left(\mathrm{X}^{\ell}, \mathrm{Y}^{\ell}, \mathrm{Z}^{\ell}\right)$ are the coordinates in image space.

At this time twelve first-order coefficients: $W_{1}$ to $W_{6}$ for the entrance boundary, and $W_{1}$ to $W_{6}$ for the exit boundary, may be printed out. These twelve are labeled by $R$ followed by the field number. This option is called the ray trace. The $W^{\prime}$ 's are defined by the equations

$$
\mathrm{Y}^{\mathrm{N}}=\mathrm{w}_{1}^{\mathrm{N}} \alpha+\mathrm{w}_{2}^{\mathrm{N}} \beta+\mathrm{w}_{3}^{\mathrm{N}} \gamma+\mathrm{w}_{4}^{\mathrm{N}} \delta
$$

and

$$
\mathrm{z}^{\mathrm{N}}=\mathrm{w}_{5}^{\mathrm{N}} \alpha_{\mathrm{z}}+\mathrm{w}_{6}^{\mathrm{N}} \delta_{\mathrm{z}}
$$

Just before the program summary a line labeled RS is read out, which contains $\mathrm{W}_{1}$ to $\mathrm{W}_{6}$ calculated at the collector point.

After the last field calculation has been completed, the program begins a summary calculation. This summary includes the aberration coefficients for the collector plane and other constants of the system. Eighteen coefficients $B_{1}$ to $B_{18}$, labeled $S 1$, are read out. They are 
defined by the equations

$$
\begin{aligned}
\frac{\mathrm{Y}^{\mathrm{N}}}{\mathrm{r}^{\ell}}= & \mathrm{B}_{1} \alpha+\mathrm{B}_{2} \beta+\mathrm{B}_{3} \gamma+\mathrm{B}_{4}\left(\frac{\delta}{\mathrm{r}^{1}}\right)+\mathrm{B}_{7} \alpha^{2}+\mathrm{B}_{8} \alpha \beta+\mathrm{B}_{9} \beta^{2}+\mathrm{B}_{10} \alpha \gamma+\mathrm{B}_{11} \beta \gamma+\mathrm{B}_{12} \gamma^{2} \\
& +\mathrm{B}_{13} \alpha\left(\frac{\delta}{\mathrm{r}^{1}}\right)+\mathrm{B}_{14} \beta\left(\frac{\delta}{\mathrm{r}^{1}}\right)+\mathrm{B}_{15}\left(\frac{\delta}{\mathrm{r}^{1}}\right)^{2}+\mathrm{B}_{16} \alpha_{\mathrm{Z}}^{2}+\mathrm{B}_{17} \alpha\left(\frac{\delta_{\mathrm{z}}}{\mathrm{r}^{1}}\right)+\mathrm{B}_{18}\left(\frac{\delta_{\mathrm{z}}}{\mathrm{r}^{1}}\right)^{2}
\end{aligned}
$$

and

$$
\frac{z^{N}}{r^{l}}=B_{5} \alpha_{z}+B_{6}\left(\frac{\delta_{z}}{r^{1}}\right)
$$

Following the S1 readout is the last output record, labeled S2, which contains the following six constants in order;

(1) the position of the axial focusing plane, i.e., the distance $\mathrm{X}^{\ell}$ to the point where $B_{5}=0$;

(2) the system mass dispersion per $\triangle M / M$;

(3) the radial image magnification (measured at the point of $\alpha$ focus, i.e., where $B_{1}=0$ );

(4) the axial image magnification (measured at the point of $\alpha_{z}$ focus, i.e., where $\left.B_{5}=0\right)$;

(5) the angle $\psi_{\alpha}$ that the direction-focusing curve makes with the optic axis;

(6) the angle $\psi_{\beta}$ (or $\psi_{\eta}$ ) that the velocity (energy)-focusing curve makes with the optic axis.

The angles $\psi_{\alpha}$ and $\psi_{\beta}$ (or $\psi_{\eta}$ ) (see Fig. 5) are defined as follows: the locus of points of direction or $\alpha$ focus described as an ion mass or $\gamma$ is varied will be a surface in image space. The intersection of this surface with the system median plane is the direction-focusing curve $\chi_{\alpha}$. The slope, in degrees, of the tangent to $\chi_{\alpha}$ at its intersection with the optic axis is $\psi_{\alpha}$. The $\mathrm{X}^{\ell}$ coordinate of this point is the one for which $\mathrm{B}_{1}=0$. In a completely analogous manner, the velocity or energy parameters $\chi_{\beta}$ and $\psi_{\beta}$ (or $\chi_{\eta}$ and $\psi_{\eta}$ ) may be defined. The $x^{\ell}$ coordinate for the intersection of $\chi_{\beta}$ or $\chi_{\eta}$ with the optic axis is that value which makes $B_{2}=0$. The angle $\psi_{\beta}$ (or $\psi_{\eta}$ ) is of most interest for systems which are "double focusing, "that is, where $B_{1}$ and $B_{2}$ both equal zero for the same value of $X^{\ell}$.

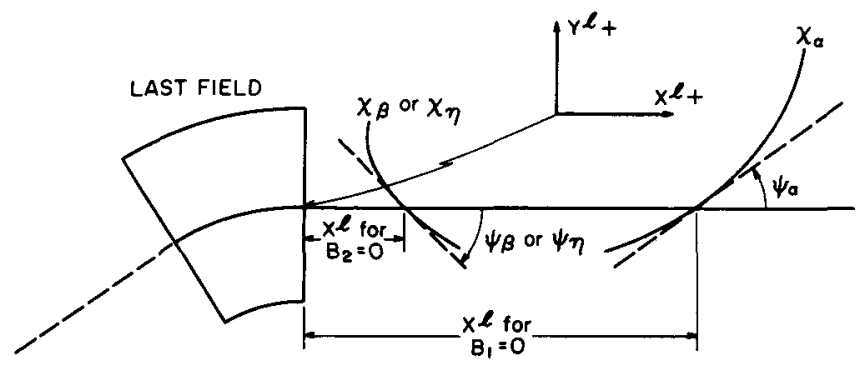

Fig. 5

Figure Illustrating the Direction and Energy Focusing Curves and the Angles These Curves Make with the Optic Axis. In this figure $\psi_{\alpha}$ is positive and $\psi_{\beta}$ is negative. 


\section{SAMPLE PROBLEM}

As an example of the use of this program consider the Argonne 100-in. mass spectrometer, shown pictorially in Fig. 6. This instrument consists of a $100-i n .-r a d i u s, 75^{\circ}$ spherical electrostatic analyzer, followed by a $100-$ in.-radius, $110^{\circ}$ magnetic analyzer.

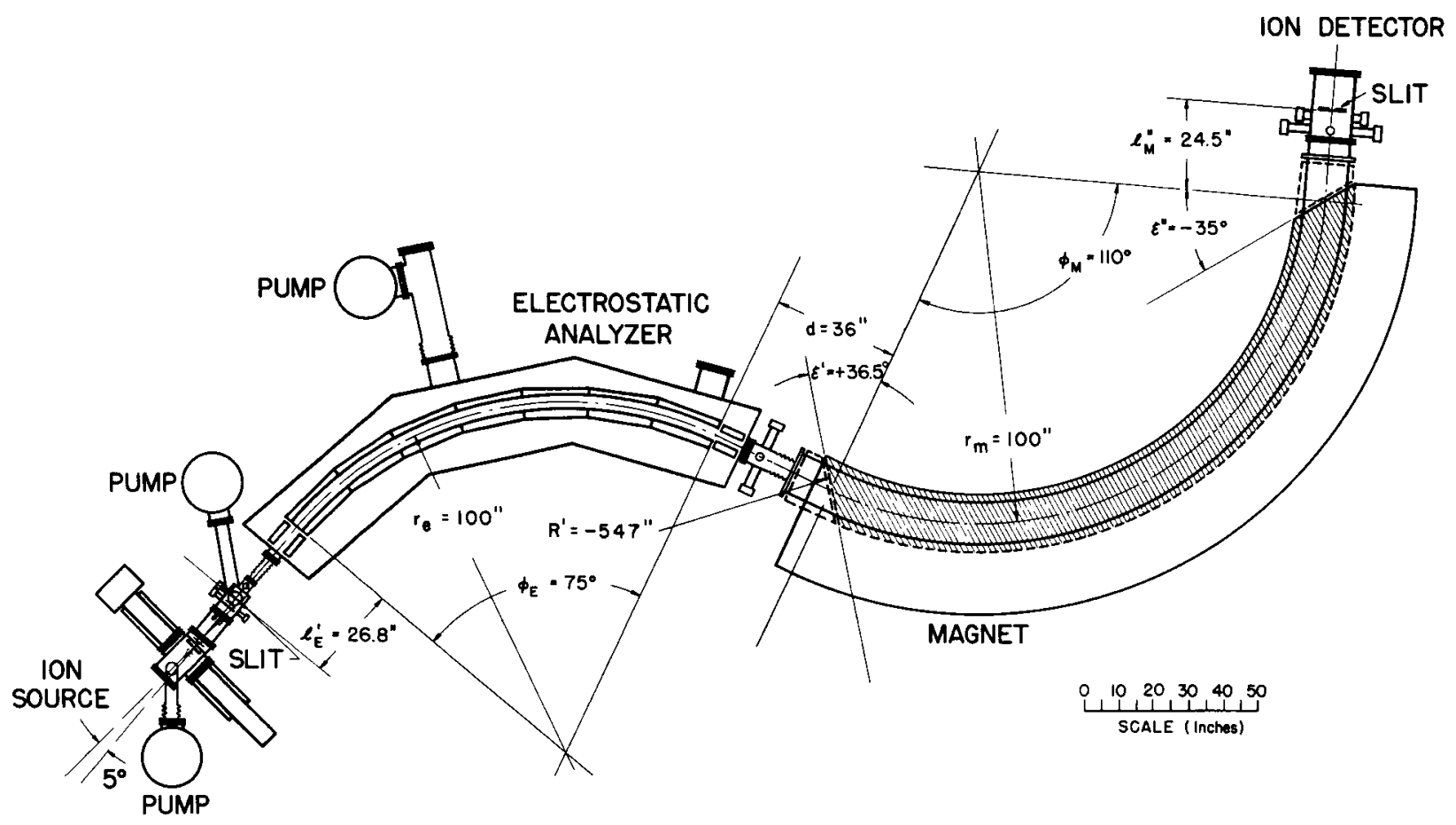

Fig. 6. 100-in. Radius Double Focusing Mass Spectrometer

The parameters to be used in this example were read off Fig. 6 and punched on data cards as in Table II. The program output listing is shown in Table III, in which the second Sl and S2 outputs are for the energy ( $\eta$ ) rather than the velocity $(\beta)$ representation used in the preceding output records.

The ray trace feature was used to calculate the curves plotted in Figs. 7A and 7B. For this calculation the electric and magnetic sectors were each divided into ten subfields zero distance apart. The ray trace, output for these twenty fields gave enough points to plot the curves. This output takes into account first-order* terms only, i.e., rays an infinitesimal distance away from the optic axis. In the figures the dimensions measured perpendicular to the optic axis can be considered greatly magnified. For this reason the magnetic sector boundaries are shown at right angles to the optic axis rather than inclined as they look to rays at a finite distance away. However, the calculation does take into account the focal properties of non-normal entrance and exit from the magnetic field.

*Second-order terms could easily be taken into account by calculating the curves directly from the coefficient print feature. 
Table II

INPUT DATA FOR SAMPLE PROBLEM

COST CODE

\begin{tabular}{|c|c|c|c|c|c|c|c|c|c|c|c|c|c|}
\hline PROGRAM & & & PROBL & & & ORIG & N AT OR & & & TE & & PAGE & OF \\
\hline & & 1 & & 2 & 3 & 3 & 4 & & 5 & 16 & & 7 & 8 \\
\hline 123456 & 789 & $\begin{array}{lll}0 & 1 & 2\end{array}$ & 345678 & $9 \mid \begin{array}{lllll}0 & 1 & 2 & 3 & 4\end{array}$ & $\begin{array}{llllll}5 & 6 & 7 & 8 & 9 & 0\end{array}$ & 123456 & \begin{tabular}{lll|lll}
78 & 9 & 0 & 1 & 2 \\
\end{tabular} & $345 \in 78$ & 9010123 & $\begin{array}{llllll}5 & 6 & 7 & 8 & 9 & 0\end{array}$ & 123456 & $\begin{array}{l}789 \\
\end{array}$ & 34567890 \\
\hline $1.17,51$. & L.11 & 0.01. & $1,12,61.18$ & $11 \perp 11$ & $1 \perp 1 \perp 1$ & 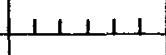 & $1 / 1 / 1$ & $11,11$. & $1 \perp 1_{1} 1_{1}$. & $1,1 \ldots 1$ & $1,1,1,1$ & 2 & 1 \\
\hline عـ1,1,1, & لــــ & $10,01$. & 11114 & $1,13161$. & 12141.15 & $1-15,4,7,$. & $1+111$ & $1,3,6,15$ & $\perp \perp, 1,5,$. & 11111 & $1,1 \quad 1 \quad 12$ & 11112 & $1,4,1,1,1,1,1$ \\
\hline $1+17,51$. & 1.1 & 10,0 , & 1.12161 .18 & 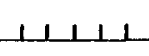 & $1,1,11$ & 1 & 11111 & $1 \perp 11$. & $\perp \perp \perp_{1} l_{1}$ & 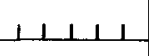 & $1,1,11$ & $111 \perp 12$ & $2_{1}, \ldots, 1,1$ \\
\hline $11_{1} 1_{1} 0_{1}$. & 11 & $10,01$. & 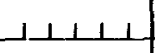 & $1,13,6$. & $1,2,41.15$ & $1-15,4,71$. & $\perp \perp \perp 11$ & $1,3,6,1.15$ & 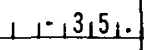 & 11111 & $1+1,12$ & $1,1,2$ & $1,4,1,1,1,1$ \\
\hline 11111 & 11 & $1 \perp$ & $1 \perp \perp \perp 1$ & LـL & 11111 & 1,111 & $1 / 111$ & 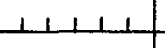 & 1,111 & $\perp 1111$ & $\perp \perp \perp 11$ & 11111 & 1 \\
\hline 1.11 & 11 & 1,1 & $1,1,1$ & 11111 & 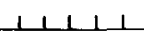 & $\perp \perp \perp 11$ & $1 \perp \perp \perp 1$ & $\perp \perp 1 \perp 1$ & 11111 & $\perp 1\llcorner 1$ & $\perp \perp \perp \perp 1$ & 11111 & 1111111 \\
\hline $1 \perp \perp \perp 1$ & 11 & 111 & 11,11 & 11111 & 111111 & 11111 & 11111 & 11111 & $1 \perp \perp 11$ & $1 \perp 111$ & 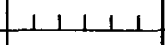 & $1 \perp \perp 11$ & $1 \perp \perp \perp \perp \perp$ \\
\hline 11111 & Lـــ L & 111 & $\begin{array}{lllll}1 & 1 & 1 & 1 & 1\end{array}$ & $1+111$ & 11111 & 11111 & 11111 & $11+11$ & 11111 & $11 / 11$ & $\mid \begin{array}{llll}1 & 1 & 1 & 1\end{array}$ & $11<11$ & $\perp \perp 1 \mid \perp \perp$ \\
\hline $1 \perp \perp 11$ & 11 & 111 & 11111 & L | & 111.1 .1 & 11111 & 11111 & 11111 & $1+111$ & 11111 & 11111 & 11111 & 111111 \\
\hline$-\perp \perp|1|$ & $\perp \perp$ & 111 & $1 \sqcup 111$ & L & $1 / 1,1$ & 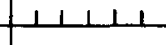 & $11 \ldots 11$ & $1 \perp \perp 11$ & 11111 & $\perp \perp \perp \perp$ & $\perp \perp \perp \perp \perp$ & $1|1| 1$ & 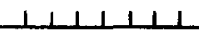 \\
\hline 11111 & 11 & 111 & 11111 & 11111 & 11111 & 11111 & 11111 & 11111 & $111 \mid 1$ & 11111 & 111111 & 11111 & 1111111 \\
\hline 111111 & لـــــــ & 111 & $1 \perp \perp \perp \perp$ & 11111 & $\perp \perp \perp \perp \perp$ & +11111 & $\begin{array}{llllll}1 & 1 & 1 & 1 & 1 & 1\end{array}$ & $11 \perp 11$ & $1 \perp 1 \perp 1$ & 11111 & $1+1 \mid 1$ & 11111 & 1111111 \\
\hline $1 \perp \perp \perp \ldots$ & لــــــ & 111 & 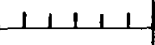 & 11111 & $1+111$ & $1 \perp \perp 11$ & 11111 & 11.11 & $\perp \perp 111$ & $\perp \perp \perp \perp \mid$ & 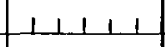 & $1 / 1 / 1$ & $1111 \perp 11$ \\
\hline 111111 & 11 & 111 & $1+111$ & 11111 & 11111 & 11111 & 11111 & 11111 & $11 \ldots 1$ & 11111 & 11111 & 11111 & 1111111 \\
\hline 11111 & 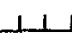 & 11 & $\perp \perp \perp \perp 1$ & 11111 & 11111 & $11 \perp 11$ & 11111 & $\perp 1 \perp 11$ & $1 \perp \perp \perp$ & 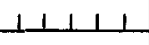 & 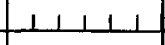 & 11111 & 1111111 \\
\hline $1 \perp 111$ & 11 & 111 & $1 \perp 111$ & 11111 & 11111 & 11111 & 11111 & 11111 & $\perp \perp \perp \perp \perp$ & $1 \perp 111$ & $\perp \begin{array}{llll}1 & 1 & 1 & 1\end{array}$ & 11111 & 11.1111 \\
\hline $1 \perp 111$ & 11 & 111 & 11111 & $|L|||$ & $1 \mid 1 \perp 1$ & $\perp \perp \perp \perp 1$ & $\perp \perp 111$ & $11 \perp 11$ & $\perp 1 \perp \perp 1$ & 11111 & $1 \perp \perp 11$ & $1 \mid \perp \perp 1$ & $-111 \mid 1111$ \\
\hline $\begin{array}{lllll}1 & 1 & 1 & 1 & 1\end{array}$ & 11 & 111 & 11111 & 11111 & $\perp \perp \perp 1$ & 11111 & $1 \perp 1111$ & $-11 \perp \perp 1$ & $1 \perp \perp \perp 1$ & 11111 & $\left|\begin{array}{lllll}1 & 1 & 1 & 1 & 1\end{array}\right|$ & 11111 & 1111111 \\
\hline$\perp 1111$ & 11 & 111 & $\begin{array}{lllll}1 & 1 & 1 & 1 & 1\end{array}$ & 11111 & 11111 & $1|\perp| 1$ & 11111 & 11111 & $1 \quad 1 \quad 1 \quad 1 \quad 1$ & $\begin{array}{lllll}1 & 1 & 1 & 1 & 1\end{array}$ & 111111 & 111.11 & 1111111 \\
\hline 11111 & 1 & 1 & $1 \perp \perp \perp$ & $4+111$ & 11114 & $\perp=1|\perp| 1$ & 11111 & 11111 & $1 \perp 1 \perp 1$ & 11111 & $\left.\begin{array}{lllll}1 & 1 & 1 & 1 & 1\end{array}\right]$ & 111111 & 1111111 \\
\hline 123456 & 789 & $\begin{array}{lll}0 & 1 & 2\end{array}$ & 345678 & $9 \quad 011234$ & \begin{tabular}{lllll|l}
5 & 6 & 7 & 8 & 9 & 0 \\
\end{tabular} & 123456 & $\begin{array}{ll}789 & 8 \\
\end{array}$ & 345678 & 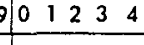 & $\begin{array}{llllll}5 & 6 & 7 & 8 & 9 & 0\end{array}$ & 123456 & 7899012 & 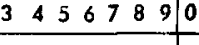 \\
\hline & & 1 & & 2 & 3 & & 4 & & 5 & 6 & & 7 & 8 \\
\hline
\end{tabular}


Table III

\section{SAMPLE PROBLEM OUTPUT}

C 1

R 1

c 2

R 2

RS

$s 1$

s2

S1

s2

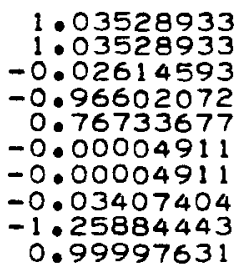

0.99997631

26.80000000 26.80000000

0.00000000

$-0.36573166$ $-0.43555374$

$-10.52564577$

1.82385587

$-2.26343107$

1.49091663

$-1.07108789$

0.81198440

$-3.41156817$

2.62351919

103.52716495 67.10100965

$-0.04570846$ $-69.79702763$

$-0.00045708$ $-0.69797028$

$-10.32670959$

0.98802167

$-1.62066887$

$-40.66461282$ 48.56350975
1.48236198

0.25881901

0.00000000

3.73205088

0.09591587

1.93185167

$-0.96592584$

0.00000000

2.93185155

$-0.23296295$

0.00000000

1.00000000

0.25881901

$-1.24278774$

$-1.81704510$

$-0.70047860$

$-2.17157112$

$-0.32902210$

5. 06829209

$-2 \cdot 17244144$

$-0.74548292$

9.73563290

$-0.21561004$

$-217.78285810$

$-0.08891429$

0.93908818

$-0.10561756$

$-2.34929325$

$-0.00105618$

$-2 \cdot 34929325$

$-0.88312192$

0.21365894
-0.38184657

67.10100859

48.56285248
0.00000000

$-0.00004912$

0.00000000

$-0.93301272$

0.00000000

$-1.03534018$

0.00000000

$-0.24999997$

0.00000000

103.52893304

103.52893304

0.67101010

0.19775253

$-2.61798160$

0.57892024

$-0.00000004$

$-0.60531209$

$-1.56822031$

$-1.72109583$

$-0.00000000$

$-36.57316597$

$-43.55537433$

$67 \cdot 10100859$

0.67101009

0.04945107

$-3.00219557$

0.15725176

0.67072831
0.25881901

3.86389310

0.00000000

$-0.26774917$

$-0.96592584$

3.03542511

0.00000000

0.03472601

1.00000000

148.23619794

0.25881901

0.93908818

$-9.78742093$

$-0.16775250$

$-0.33628085$

$-1.09397747$

12.63628107

0.00000003

$-0.33287384$

0.08891429

$-124.27877381$

$-1.81704510$

0.67106371

0.67106371

$-6.69153207$

$-0.16775250$

$-0.41783494$

$-0.93363020$
0.67101009

0.04945107

$-1.50109779$

0.15725176

0.67072831
0.67106371 $-3.34576604$ $-0.16775250$ $-0.41783494$

0.10682947

$-0.38184657$

67.10100859 48.56285248

$-0.93363020$
$-40.66461282$ 48.56350975 


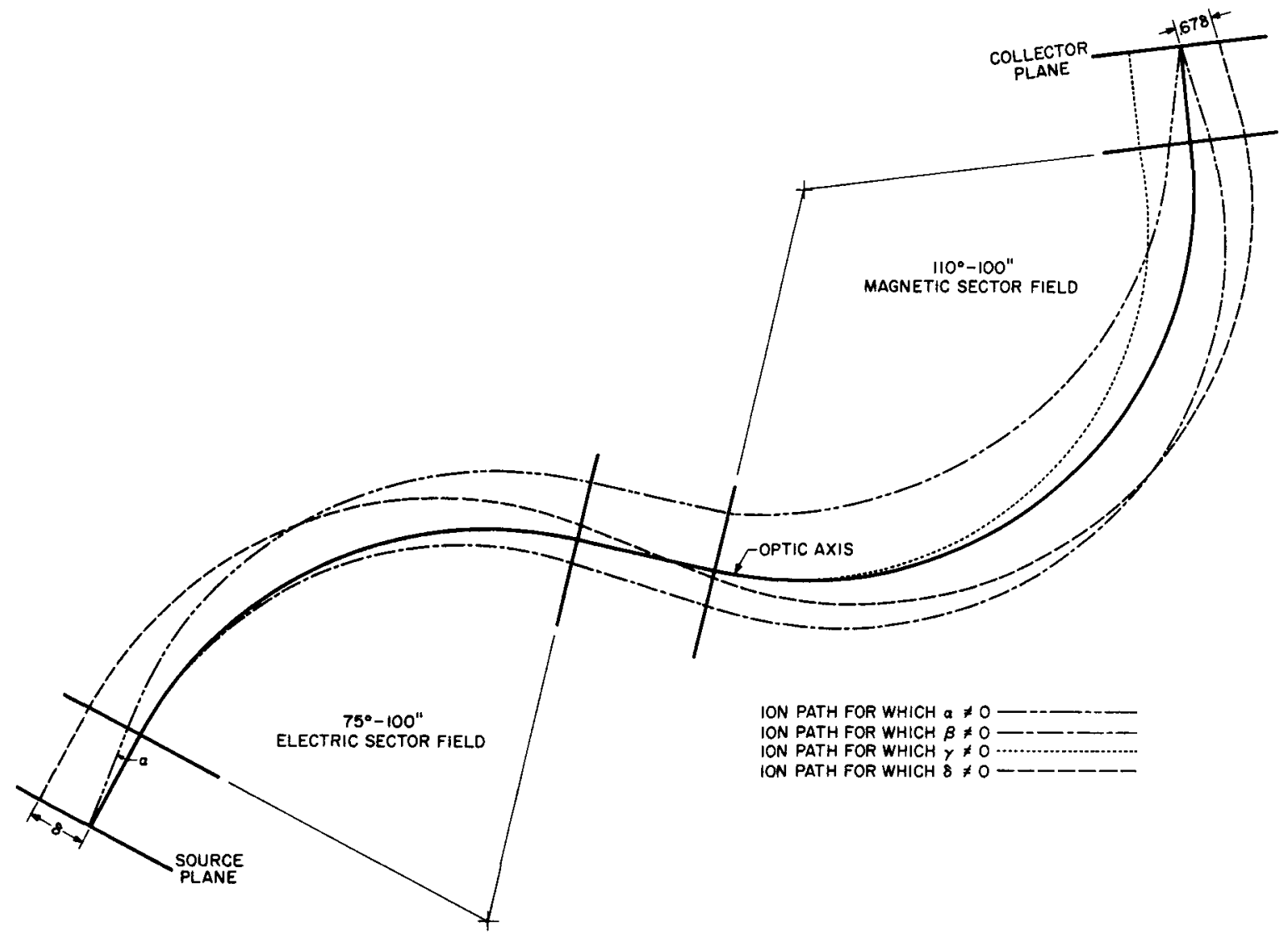

A. Radial Plane

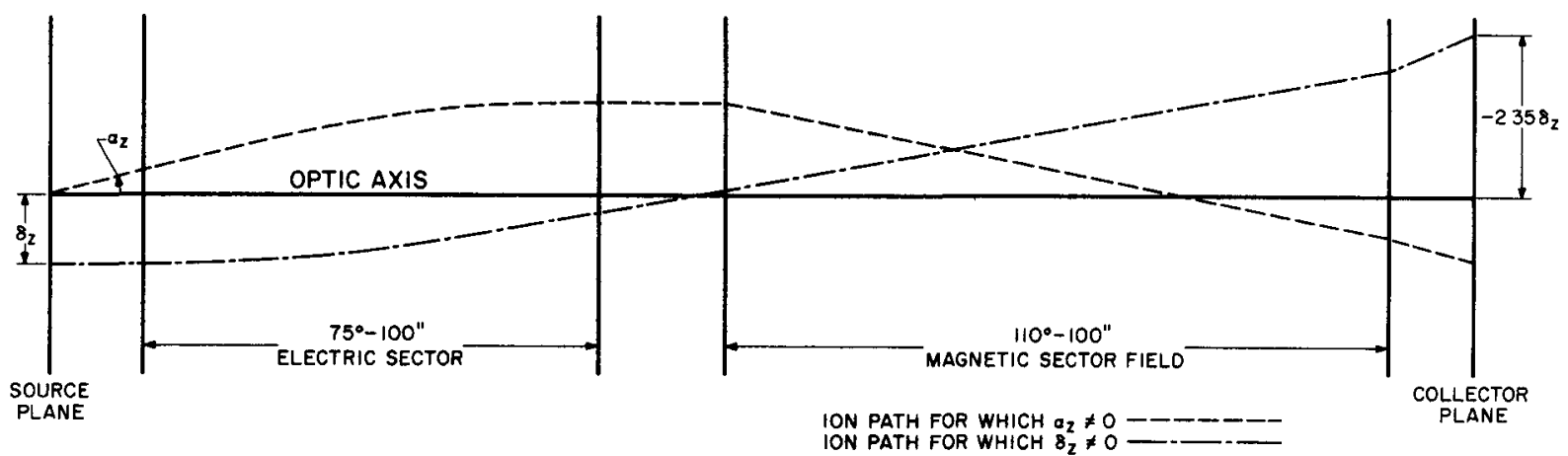

B. Axial Plane

Fig. 7. First-order Approximation to the Ion Trajectories for the Argonne 100 -in. Mass Spectrometer. These plots were found by use of the ray trace feature of the program. Note that the distance in the radial and axial directions are shown greatly magnified. 


\section{REMARKS}

The program described in this report is primarily for system analysis. It would be considerably more difficult to write a general computer program for system synthesis since each designer may wish to optimize different parameters. A few special syntheses of general interest have been intensively studied by groups in Germany and the Netherlands. $(8)$

No account is taken of the fringing fields, except for the $\mathrm{Z}$ or axial focusing effect of non-normal entrance into magnetic fields. In this case the fringing fields act as thin lenses with focal length equal to the field radius divided by the tangent of $\epsilon$ (defined in Fig. 2). The fringing field of electrostatic analyzers is usually eliminated by the use of Herzog end shields. (9) The effects of the magnetic fringing fields can be taken into account by finding a field without fringing effects equivalent to an actual field and using this equivalent field in the computer calculations. Some help in finding this equivalent field can be found in the paper by Coggeshall and Muskat.(10)

From the discussions given in the papers listed at the beginning of this report one can see that the second-order radial coefficients depend on the radii of curvature of the field boundaries, but that the first-order coefficients and the general system properties do not. In fact, the secondorder coefficients are linear functions of the reciprocals of these radii. With curved field boundaries, the ions traveling off the optic axis see slightly more or less field than those moving along the optic axis. Balestrini and White(li) have suggested the use of magnetic shims to give the same effect as the curved field boundaries. An alternative suggestion made by C. Stevens $(12)$ is to use small coils, similar to Hemholtz Coils, at various places along the ion path in the magnetic field. These coils have the advantage that the current through them can be varied, thus allowing some "tuning" of the instrument. The following example illustrates the use of this program in planning these methods of aberration correction.

Example: Consider three coils placed at the entrance, the middle, and the exit of the 100-in. mass spectrometer magnet used in the sample problem (p. 12). We wish to find the coil field strengths which will make $B_{11}=0$ and $\left|B_{12}\right|+\left|B_{22}\right|$ a minimum. It is convenient to measure the coil field strengths in units of effective boundary radii of curvature, which can be related to the coil currents for a given coil construction. A practical upper limit of coil field strength or minimum radius of curvature may be set at 10 in.

Solution: Since $B_{11}, B_{12}$, and $B_{22}$ are linear functions of the reciprocals of the coil strengths, they can be written as

$$
\mathrm{B}_{11}=\frac{\mathrm{C}_{1}}{\mathrm{R}_{1}}+\frac{\mathrm{C}_{2}}{\mathrm{R}_{2}}+\frac{\mathrm{C}_{3}}{\mathrm{R}_{3}}+\mathrm{C}_{4} ;
$$




$$
\begin{aligned}
& B_{12}=\frac{C_{5}}{R_{1}}+\frac{C_{6}}{R_{2}}+\frac{C_{7}}{R_{3}}+C_{8} ; \\
& B_{22}=\frac{C_{9}}{R_{1}}+\frac{C_{10}}{R_{2}}+\frac{C_{11}}{R_{3}}+C_{12},
\end{aligned}
$$

where the $C^{\prime} s$ are constants, and $R_{1}, R_{2}$, and $R_{3}$ are the coil field strengths. To find the $C^{\prime} s$, set all three $R^{\prime}$ s equal to infinity and obtain $C_{4}, C_{8}$, and $C_{12}$ by use of this program. Next, take any three linearly independent sets of $\left(R_{1}, R_{2}, R_{3}\right)$ and calculate the $B$ coefficients for each set. This procedure gives three sets of three linear simultaneous equations which can be solved for the nine remaining $C^{\prime} s$. At this point we have,

$$
\begin{aligned}
& \mathrm{B}_{11}=\frac{71.67}{\mathrm{R}_{1}}+\frac{61.09}{\mathrm{R}_{2}}+\frac{2.981}{\mathrm{R}_{3}}+0.1805 ; \\
& \mathrm{B}_{12}=\frac{301.5}{\mathrm{R}_{1}}+\frac{372.7}{\mathrm{R}_{2}}+\frac{20.26}{\mathrm{R}_{3}}-6.140 ; \\
& \mathrm{B}_{22}=\frac{317.2}{\mathrm{R}_{1}}+\frac{568.4}{\mathrm{R}_{2}}+\frac{34.42}{\mathrm{R}_{3}}-9.747
\end{aligned}
$$

The magnetic field is broken into two separate fields, zero distance apart, for calculating the effects of the middle coil. Setting the B's equal to zero and solving for the R's yields a physically unrealizable result. However, the stated problem of making $B_{11}=0$ and $\left|B_{12}\right|+\left|B_{22}\right|$ a minimum, subject to the conditions $\left|R_{i}\right| \geq 10$, can be solved by straightforward linear programming methods.(13) The solution is $R_{1}=-28.912, R_{2}=23.528, R_{3}=-10$, and minimum of $\left|\mathrm{B}_{12}\right|+\left|\mathrm{B}_{22}\right|=2.755$. Other simple synthesis problems can be handled by similar methods.

\section{THE FORTRAN PROGRAM}

The program was written in "basic" Fortran through use of the most elementary forms of Fortran statements. All input-output statements are written for cards and are enclosed by lines of asterisks. This program should be easy to adapt to any computer installation. The program running time is negligible, the CDC 3600 machine at Argonne compiled the program in $35 \mathrm{sec}$ and calculated about 120 fields per minute. A program flowchart (Fig. 8) and listing (Table IV) follow. 


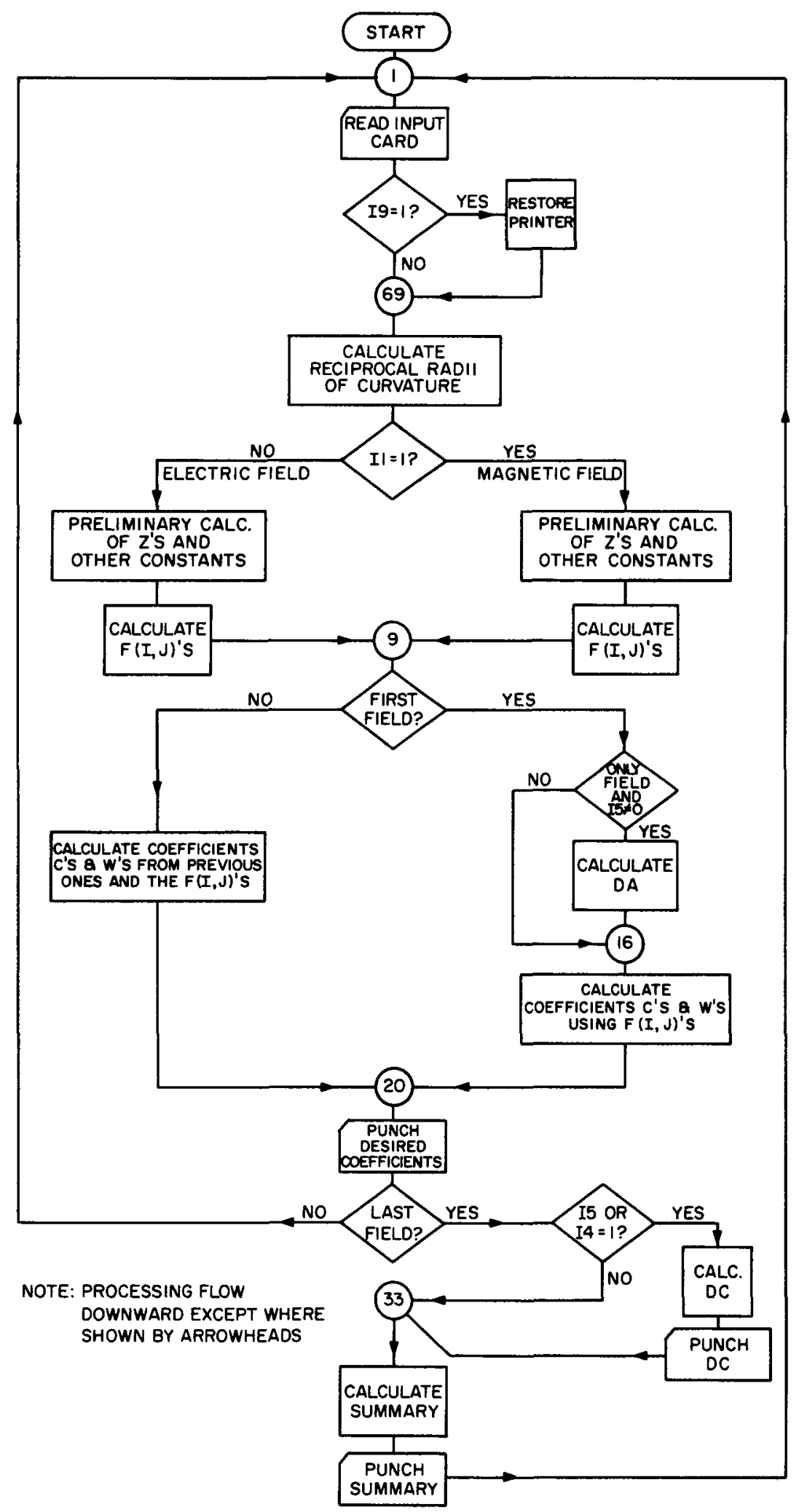

Fig. 8. Fortran Program Flowchart 


\section{Table IV}

\section{FORTRAN PROGRAM LISTING}

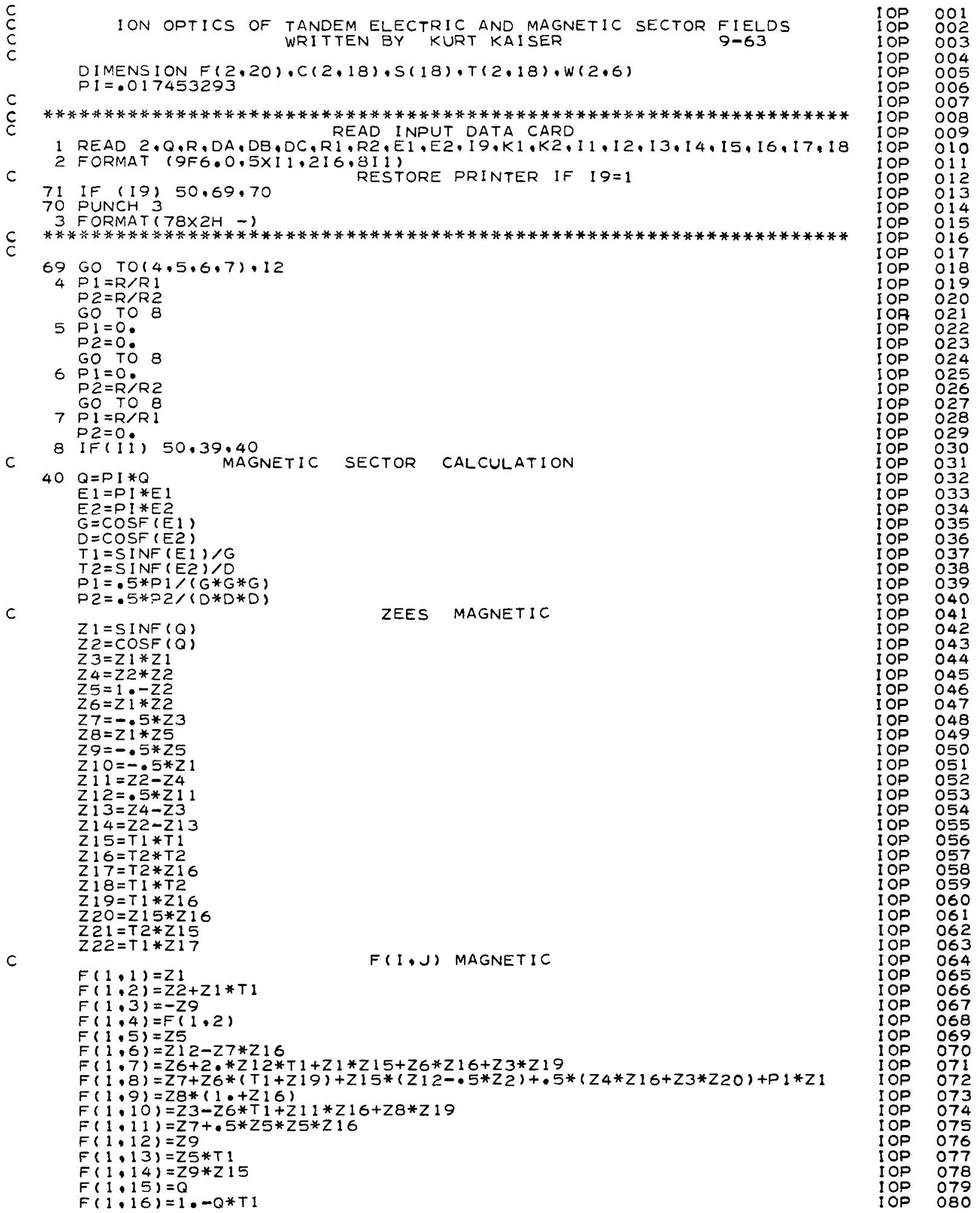


Table IV (Contd.)

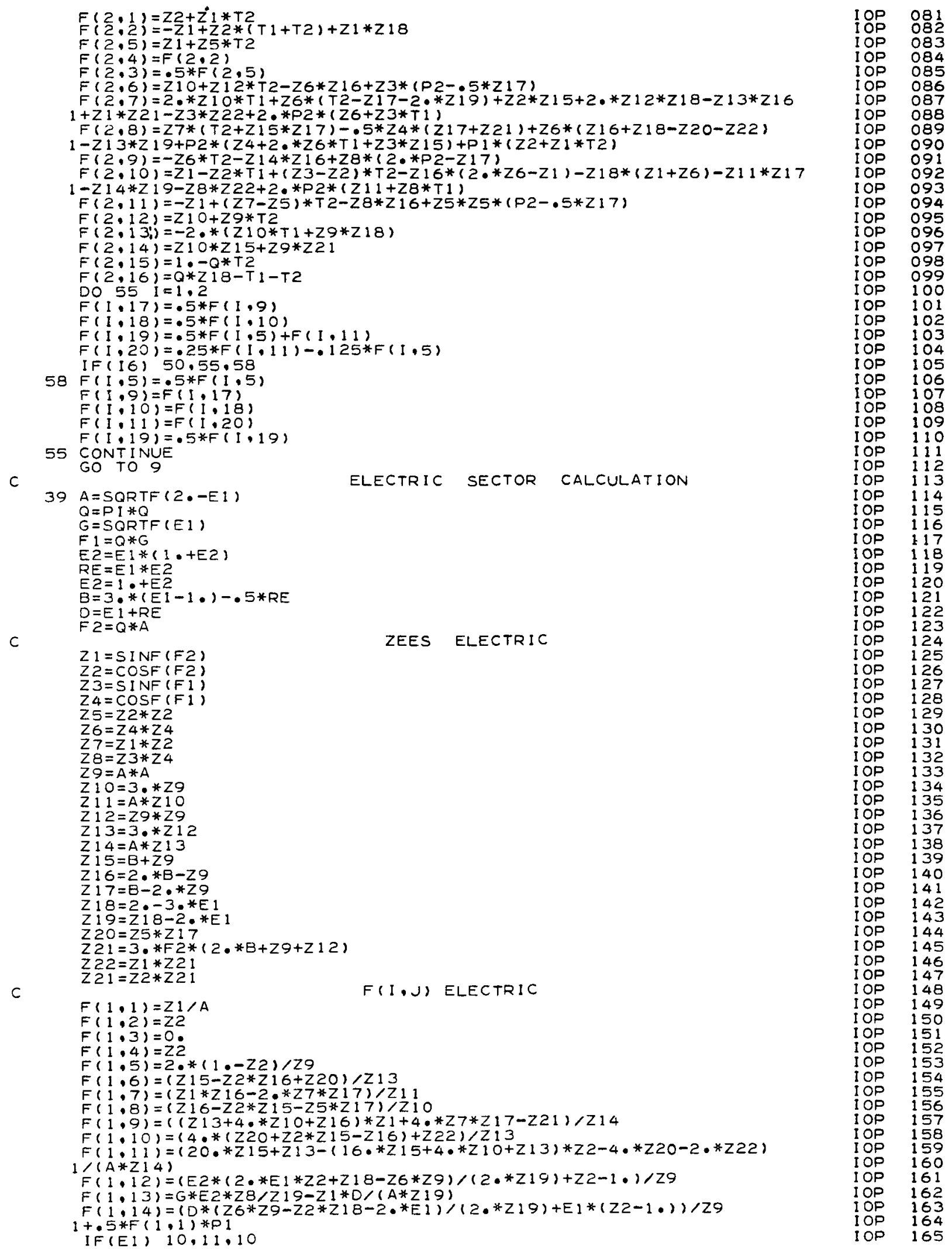


Table IV (Contd.)

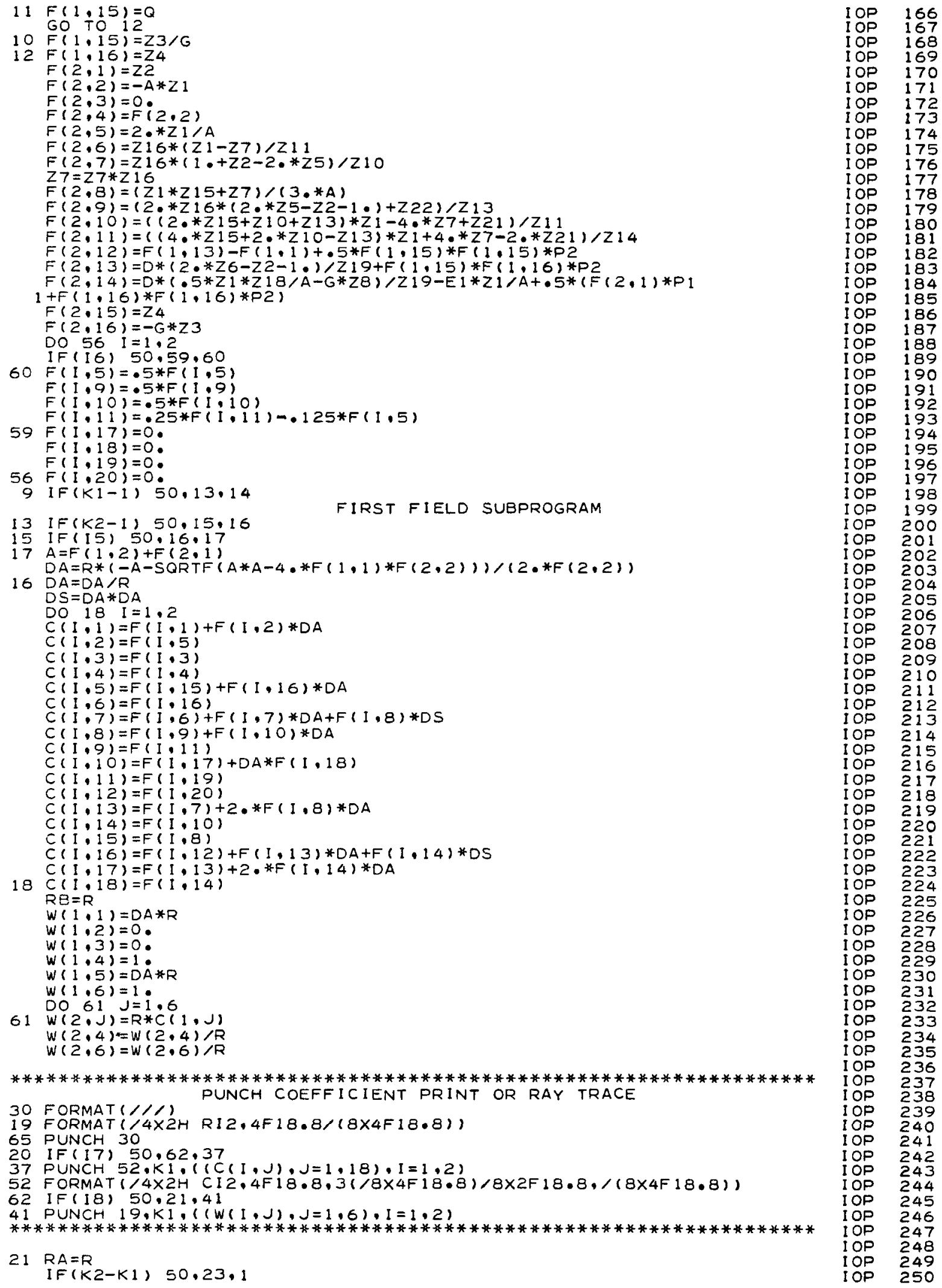


Table IV (Contd.)

C

14 DO $44, J=1.6$

MORE THAN I FIELD COMBINATION SUBPROGRAM

$W(1, j)=R * C(1, j)+D B * C(2, J)$

IF (I 3 ) $50,44,82$

82 I F $(J-5), 83,44,44$

$83 W(1, J)=-W(1, J)$

44 CONTINUE

$W(1.4)=W(1.4) / R B$

$W(1,6)=W(1,6) / R E$

$U=R A / R$

$V=D E / R$

DO $24 J=1.18$

$24 S(J)=U * C(1, J)+V * C(2, J)$

IF ( I3) $50.25 \cdot 26$

26 DO $27 \quad \mathrm{I}=1.2$

$F(1,1)=-F(1,1)$

$F(1,2)=-F(1,2)$

$F(1,9)=-F(1,9)$

$F(1,10)=-F(1,10)$

$F(1,17)=-F(1,17)$

$27 F(1,18)=-F(1,18)$

$25 D_{1}=C(2,1)$

$D 2=C(2,2)$

$03=C(2,3)$

$D 4=C(2.4)$

$H 3=C(2,5)$

$\mathrm{H} 4=\mathrm{C}(2,6)$

DO $28 \quad I=1,2$

DO $28 \quad J=1,18$

$28 T(1, J)=F(I, 1) * C(2, J)+F(I, 2) * S(J)$

Do $291=1,2$

$C(1,1)=T(I, 1)$

$C(1,2)=T(I, 2)+F(1,5)$

$C(1,3)=T(1,3)+F(1,3)$

$C(1,4)=T(I, 4)$

$C(I, 5)=F(I, 15) * H 3+F(1,16) * S(5)$

$C(1,6)=F(1,15) * H 4+F(1,16) * S(6)$

$C(1,7)=T(1,7)+F(1,6) * D 1 * D 1+F(1,7) * D(* S(1)+F(1,8) * S(1) * S(1)$

$C(1,8)=T(1,8)+2 * F(1,6) * D 1 * D 2+F(1,7) *(D 1 * S(2)+D 2 * S(1))$

$1+2 * F(1,8) * S(1) * S(2)+F(I, 9) * D 1+F(1,10) * S(1)$

$C(1,9)=T(1,9)+F(1,6) * D 2 * 02+F(1,7) * D 2 * S(2)+F(1,8) * S(2) * S(2)$

$1+F(1,9) * 02+F(1,10) * S(2)+F(1,1,1)$

$C(1,10)=T(1,10)+2 * F(1,6) * D 1 * D 3+F(1,7) *(D 1 * S(3)+D 3 * S(1))$

$1+2 * F(1,8) * S(1) * S(3)+F(1,17) * D 1+F(1,18) * S(1)$

$C(1,1)=T(1,11)+2 * F(1,6) * D 2 * D 3+F(1,7) *(D 2 * S(3)+D 3 * S(2))$

$1+2 * F(1,8) * S(2) * S(3)+F(1,9) * D 3+F(1,10) * S(3)+F(1,19)$

$2+F(1,17) * D 2+F(1,18) * 5(2)$

$C(1,12)=T(1,12)+F(1,6) * D 3 * D 3+F(I, 7) * D 3 * S(3)+F(1,8) * S(3) * S(3)$

$1+F(1,17) * D 3+F(1,18) * S(3)+F(1,20)$

$C(1,13)=T(1,13)+2 * * F(1,6) * D 1 * D 4+F(1,7) *(01 * S(4)+D 4 * S(1))$

$1+2 * * F(1.8) * S(1) * S(4)$

$C(1,14)=T(1,14)+2 * F(1,6) * D 2 * D 4+F(I, 7) *(D 2 * S(4)+D 4 * S(2))$

$1+2 \cdot * F(1,8) * S(2) * S(4)+F(1,9) * D 4+F(1,10) * S(4)$

$C(1,15)=T(1,15)+F(I, 6) * D 4 * D 4+F(I, 7) * D 4 * S(4)+F(1,8) * S(4) * S(4)$

$C(1,16)=T(1,16)+F(I, 12) * H 3 * H 3+F(I, 13) * H 3 * 5(5)+F(I, 14) * S(5) * S(5)$

$C(1,17)=T(I, 17)+2 * * F(1,12) * H 3 * H 4+F(1,13) *(H 3 * S(6)+H 4 * S(5))$

$1+2 * F(1,14) * S(5) * S(6)$

$29 \mathrm{C}(\mathrm{I}, 18)=\mathrm{T}(\mathrm{I}, 18)+F(I, 12) * H 4 * H 4+F(1,13) * H 4 * S(6)+F(1,14) * S(6) * S(6)$ DO $47 \mathrm{~J}=1.6$

$47 W(2, J)=R * C(1, J)$

$W(2,4)=W(2,4) / R B$

$W(2,6)=W(2,6) / R B$

c

GO TO 20

$23 S(1)=-R A * C(1,5) / C(2,5)$

SUMMARY

$S(3)=1 \cdot / C(2,1)$

$S(4)=1 \cdot / C(2,5)$

IF (I5) $50,32.31$

32 IF(14) $50,33,31$

$31 D C=-R A * C(1,1) / C(2,1)$

$\stackrel{c}{c}$

*******************************************************************

PUNCH $34,0 \mathrm{C}$

PUNCH DC

34 FORMAT $(\$ 4 \times 4 \mathrm{H}$ DC F 18.8$)$

$\stackrel{c}{c}$

$330064 \quad J=1,6$

$64 T(1, J)=R * C(1, J)+D C * C(2, J)$

$\mathrm{T}(1,4)=\mathrm{T}(1,4) / \mathrm{RB}$

$T(1,6)=T(1,6) / R B$

$D C=D C / R A$

$S(7)=C(1,3)+D C * C(2,3)$

$S(8)=C(1,10)+D C * C(2,10)$

$S(9)=C(1,11)+D C * C(2,11)$ 
Table IV (Contd.)

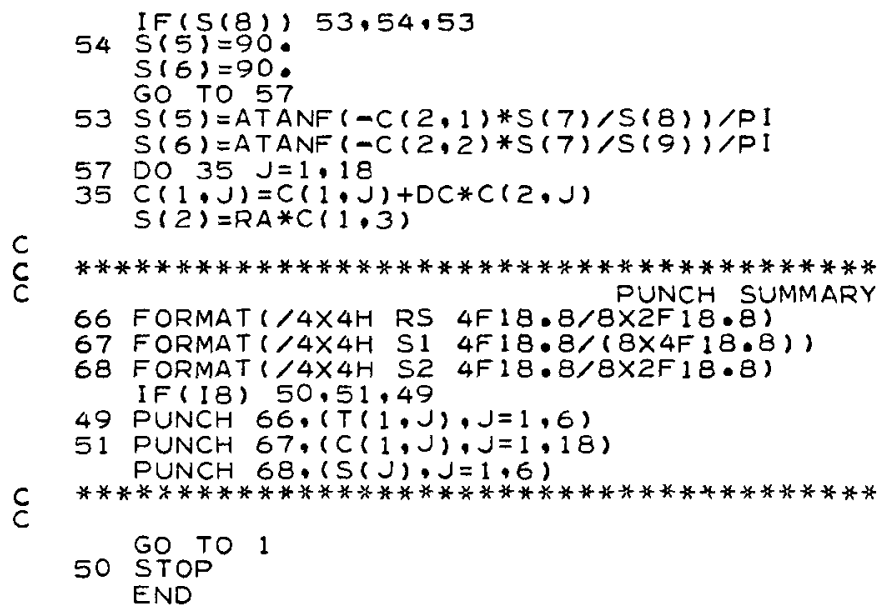




\section{REFERENCES}

1. E. G. Johnson and A. O. Nier, Angular Aberrations in Sector Shaped Electromagnetic Lenses for Focusing Beams of Charged Particles, Phys, Rev. 91, 10 (1953).

2. H. G. Voorhies, Second-order Aberrations in Sector Shaped Electromagnetic Analyzers, Rev. Sci. Instr. 26, 716-717 (1955); 27, 58 (1956).

3a. L. A. König and H. Hintenberger, Über die Abbildungsfehler von beliebig begrenzten homogenen magnetischen Sektorenfeldern, Z. Naturforsch. 12a, 377-385 (1957).

3b. H. Hintenberger and L. A. König, Mass Spectrometers and Mass Spectrographs Corrected for Image Defects, Advances in Mass Spectrometry (Ed. by J. D. Waldron), Pergamon Press (1959).

4a. H. Ewald and H. Liebl, Die Bildfehler des Toroidkondensators, Z. Naturforsch. 12a, 28-33, 588 (1957).

4b. H. Liebl, Die Schnittwinkel der Richtungs- und Energiefokussierungskurven bei doppelfokussierenden Massenspektrographen, Optik 16 , 19-26 (1959).

5a. H. A. Tasman, A. J. H. Boerboom, and H. Wachsmuth, Calculation of the Ion Optical Properties of Inhomogeneous Magnetic Sector Fields, Z. Naturforsch. 14a, 121-129, 816-827 (1959).

5b. H. A. Tasman, Ion Optics of Mass Spectrometers with Virtually Enlarged Radius, PhD. Thesis, Leiden (1961).

6. H. A. Tasman, op. cit., 5b, 64-66.

7. R. Albrecht, Das Potential in doppelt gekrümmten Kondensatoren, Z. Naturforsch. 11a, 156-163 (1956).

8. H. A. Tasman, op cit., 5b, Ch. 7. H. Hintenberger and L. A. König, op. cit., 3b: H. Liebl and H. Ewald, Z. Naturforsch. 14a, 199-200 (1959).

9. R. Herzog, Ablekung von Kathoden- und Kanalstrahlen am Rande eines Kondensators, dessen Streufeld durch eine Blende begrenzt ist, Z. Physik 97, 596-602 (1935).

10. N. D. Coggeshall and M. Muskat, The Paths of Ions and Electrons in Non-uniform Magnetic Fields, Phys. Rev. 66, 187-198 (1944).

11. S. J. Balestrini and F. A. White, Workable Magnetic Shim to Correct Second-order Aberration in a Mass Spectrometer, Rev. Sci. Instr. 31, 633-636 (1960).

12. C. Stevens, Correction Coils for Second-order Focusing with the Argonne 100 inch Radius Mass Spectrometer, Paper No. 48, meeting of ASTM Committee E-14 on Mass Spectrometry, June 1962.

13. A good introduction to this subject is given in the book by G. Hadley, Linear Programming, Addision-Wesley (1962). 